\title{
Evaluation of an Articulated Measuring Apparatus for Use in the Oral Cavity
}

\author{
Yoko MAIKUMA, Kazuhiro USUI, Kouji ARAKI ${ }^{1}$, \\ Shiro MATAKI ${ }^{2}$, Norimasa KUROSAKI and Nobuyuki FURUYA ${ }^{3}$ \\ Section of General Dentistry, Department of Comprehensive Oral Health Care, Division of Com- \\ prehensive Patient Care, \\ ${ }^{1}$ Center for Education Research in Medicine and Dentistry, \\ ${ }^{2}$ Section of Behavioral Dentistry, Department of Comprehensive Oral Health Care, Division of \\ Comprehensive Patient Care, \\ Tokyo Medical and Dental University, Graduate School \\ 1-5-45 Yushima, Bunkyo-ku, Tokyo 113-8510, Japan \\ ${ }^{3}$ Department of Mechanical System Engineering, Yamanashi University, Graduate School \\ 4-3-11 Takeda, Kofu, Yamanashi 400-0016, Japan
}

Received January 10, 2003/Accepted March 28, 2003

\begin{abstract}
The aim of this study was to evaluate the trial Teaching Robot for the development of a contact-type measuring apparatus for using directly in the oral cavity. A standard model was used to mimic the dentition by placing an arrangement of three bearing balls. The diameters of the balls were measured. A practical dentition model was used. The coordinates were measured on the top of the buccal cusp of the right and left first premolars and the distal contact points of the right and left first molars and the mesial contact point of the right incisor. The arch width and length were calculated. The diameters of the bearing balls and the widths and lengths of the dental arches were not significantly different from the results of the XYZAX G-800D. Therefore, we suggest that the trial Teaching Robot has superior efficiency for measurements in oral cavity.
\end{abstract}

Key words: Teaching Robot, Contact-type measuring apparatus, CAD/CAM

\section{INTRODUCTION}

The accurate measurement of sizes and shapes of various variables in the oral cavity is a significant factor in clinical dentistry. Precious information is obtained for determining the diagnosis, treatment, and prognosis. The apparatuses used for measuring shapes are classified into contact and non-contact types ${ }^{1)}$. Generally, the contact type has excellent accuracy and the non-contact type has convenient manipulation.

The non-contact measuring apparatus is basically composed of a light source and a reading camera. The measuring accuracy can be improved in many ways such as increasing the CCD pixel density. However, teeth, dental arch, and facial morphology have plenty of free curved surfaces. Extremely complicated shapes and manifold undercuts exist. In addition, cavities have deep and narrow concavities. Therefore, there is a lack of appropriate data in sharply angled locations. Divided measurements are taken ${ }^{2,3)}$ or many cameras are used to compensate for these areas. 
However, the data processing is complicated and capable of causing increased errors of measurement in subjects. In addition, the color and quality of measured objects may affect the permeation, reflection, and scattering of the light source ${ }^{4-14}$.

The CEREC system (Sirona, Bensheim, Germany) is typical of a dental CAD/ CAM system and one of the non-contact measuring systems. The optical impression of cavities is directly taken with an attached video camera in the oral cavity. The reparation objects are designed and shaped from ceramic blocks with the aid of a computer ${ }^{15-18)}$. However, reparation objects do not fit considerably well in the cavities, when compared with conventional reparations such as metal inlays or indirectly composite resin inlay. The main factor in this discrepancy is the supposedly low accuracy of measurements.

On the other hand, the measuring apparatus of the contact type supplies more accurate data ${ }^{1920)}$, yet requires more time. Also, most of contact type measuring apparatus only have $\mathrm{X}, \mathrm{Y}$ and $\mathrm{Z}$ degrees so that approaching objects are restricted. Therefore, the measurement of undercuts and cavities is difficult and requires the devices to be capable of divided measurements. Therefore, Nakashima et al. examined the measurement performance of a general-purpose five degrees of freedom contacttype measuring apparatus with standard models, and reported that undercuts could be measured at one time without divided measurements ${ }^{21)}$. But six degrees of freedom are needed to control the optional position and posture. Up to now, the contact-type measuring apparatus with six degrees of freedom has not existed.

The aim of this study was to experimentally produce the Teaching Robot for the development of a contact-type measuring apparatus that can be used directly in the oral cavity. Also, the usefulness of the Teaching Robot in dentistry was investigated by measuring the standard and practical dentition models.

\section{MATERIALS AND METHODS}

\section{Trial teaching robot}

The articulated teaching robot (Fig.1) was experimentally produced as a contact type of measuring apparatus. The arm (the total length: about $80 \mathrm{~cm}$ ) of the Teaching Robot was connected with six aluminum alloy links and a probe (about $12 \mathrm{~cm}$ ) was installed on the tip of the arm. Therefore, the Teaching Robot has six degrees of freedom with six pivoting joints (Fig. 2). The probe is screwed to the link to use the shape according to the aim of measuring.

The angle of revolution is calculated by laser interference encoders (Laser Rotary Encoder R-1L, Canon, Tokyo, Japan) on each joint. The coordinates obtained from contact of the probe tip. The resolution is 324,000 pulses per revolution. The average accuracy of angle measurement is 14.3 seconds. The location error from the resolution is $0.017 \mathrm{~mm}$ and the location error from the average accuracy of angle measurement is $0.042 \mathrm{~mm}$. A personal computer was used for data collection and analysis.

We used a three-dimensional measuring apparatus (XYZAX G-800D, TOKYO 


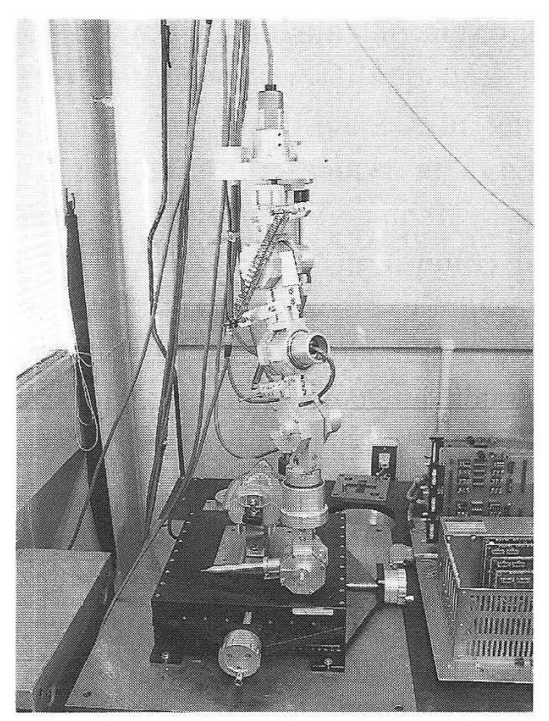

Fig. 1 Trial teaching robot.

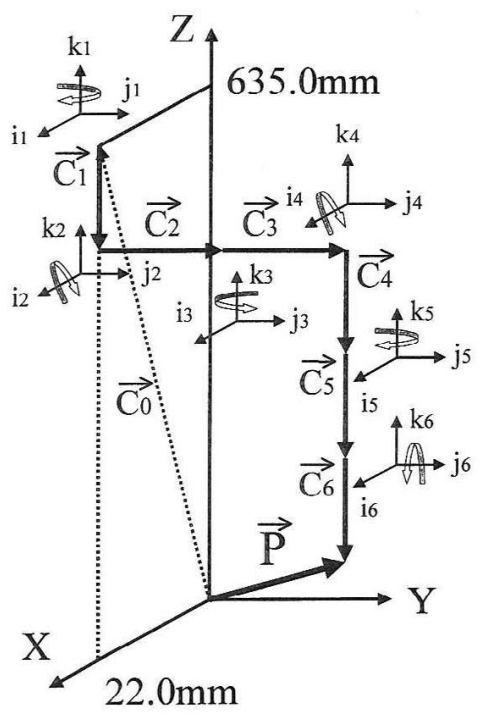

Fig. 2 Mechanism of trial teaching robot.

SEIMITU, Chiba, Japan) to verify the measurement accuracy of the trial Teaching Robot. The portal type apparatus has 3 mutually perpendicular axes. The space measurement range has been reported to be $800 \mathrm{~mm} \times 800 \mathrm{~mm} \times 600 \mathrm{~mm}$. The accuracy of each axis has been reported to be $2.0+3 \mathrm{~L} / 1000 \leqq 3.5 \mu \mathrm{m}$ with the accuracy of space at $2.5+3 \mathrm{~L} / 1000 \leqq 4.5 \mu \mathrm{m}$ ( $\mathrm{L}$ : Distance of the measured object $(\mathrm{mm})$ ).

\section{Operation of the trial Teaching Robot}

A practical dentition model (D18FE-500H, Nissin, Kyoto, Japan) was used with a rubber sheet to imitate lips, cheeks, and a tongue. The D18FE-500H was fixed to the manikin on the desk (Fig. 3) and placed on the top of the head of the manikin, based on modeling clinical trcatment. The probe of the trial Teaching Robot was inserted into the oral cavity of the manikin and allowed to contact the surface of the artificial teeth. The operation of the trial Teaching Robot was then inspected.

\section{Measurement of the standard model}

The model had a metal block to replicate the base of the maxillary dentition. Three bearing balls (spherical accuracy: $10 \mu \mathrm{m}$ ) were arranged at positions to correspond with the incisive papilla (Sphere A), the left first molar (Sphere B), and the right first molar (Sphere C). Spheres A and B had a diameter of $16 \mathrm{~mm}$, and Sphere C had a diameter of $12 \mathrm{~mm}$. Sphere A was placed at a depth of $4 \mathrm{~mm}$ relative to the upper surface of the base. Sphere B was sunk into a depth of $6 \mathrm{~mm}$. Sphere C was sunk into a depth of $4 \mathrm{~mm}$. The three spheres were fixed with an adhesive. We used this standard model for mimic dentition (Fig. 4).

The reason that the spheres are used is as follows. It is very difficult to measure the same point over and over with a contact-type measuring apparatus. The 


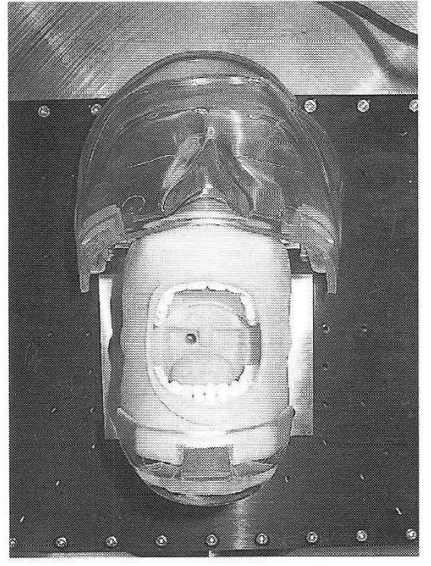

Fig. 3 Practical dentition model.

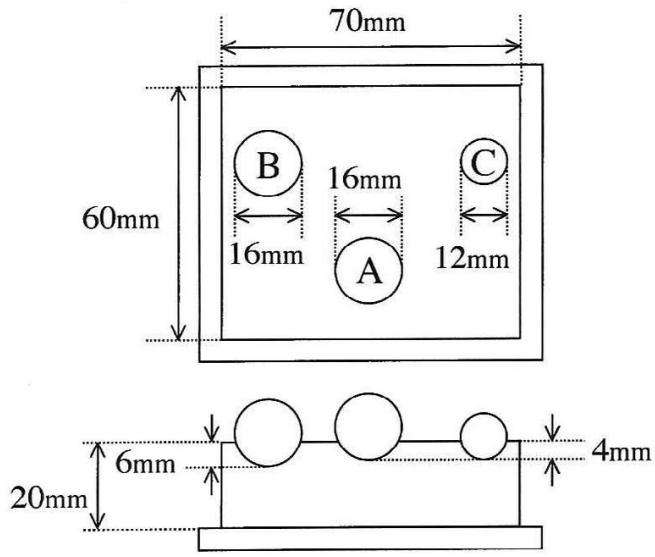

Fig. 4 Standard model.

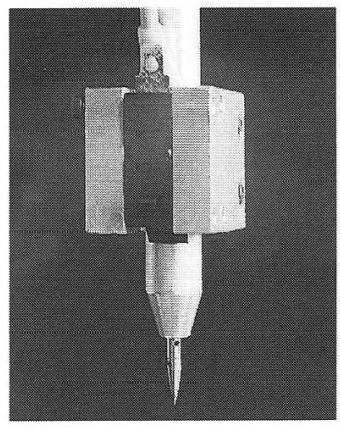

Fig. 5 Probe.

spherical center and the radius are calculated with the coordinates of the optional spherical surface points. Therefore, it is appropriate for the verification of the measuring accuracy. The sphere is sunk in optional depth relative to the base, and various maximum projections and undercuts are got ${ }^{7,21,22)}$.

The standard model was fixed on the desk. The trial Teaching Robot with a metal needle-shaped probe (Fig.5) and the XYZAX G-800D with a spherical probe (diameter $=2 \mathrm{~mm}$ ) were used for measuring the diameters of the three spheres. Namely, the coordinates of four optional points on each sphere were found. The diameters were calculated with expression (1) for each sphere. The measurements were repeated five times. The data were analyzed statistically with the Student's t-test. Values to the second decimal place were regarded as valid.

$(\mathrm{X}-\mathrm{s})^{2}+(\mathrm{Y}-\mathrm{t})^{2}+(\mathrm{Z}-\mathrm{u})^{2}=\mathrm{r}^{2}$

$(\mathrm{X}, \mathrm{Y}, \mathrm{Z})$ : the coordinates of the point on the sphere

$(s, t, u)$ : the coordinates of the sphere's center

$r$ : the radius

\section{Measurement of the practical dentition model}

Using the trial Teaching Robot, the lengths and widths of the upper and lower dental arches were measured (Fig.6) in the practical dentition model fixed to the manikin. The coordinates were measured on the top of the buccal cusp of the right and left first premolars. The arch width was calculated with expression (2). The right and left second molars and the left upper and lower incisors were then removed. The distal contact points of the right and left first molars and the mesial contact points of the right incisors were marked, and their coordinates were measured. The arch length was calculated with expression (3).

For the XYZAX G-800D, the practical dentition model was fixed on the desk. In 
the same method as the trial Teaching Robot, the dental arch lengths and widths were measured.

$\mathrm{W}=\sqrt{\left(\mathrm{x}_{2}-\mathrm{x}_{1}\right)^{2}+\left(\mathrm{y}_{2}-\mathrm{y}_{1}\right)^{2}+\left(\mathrm{z}_{2}-\mathrm{z}_{1}\right)^{2}}$

$\mathrm{W}$ : the dental arch width

$\left(x_{1}, y_{1}, z_{1}\right),\left(x_{2}, y_{2}, z_{2}\right)$ : the coordinates of the buccal cusp of the right and left first premolars

$\mathrm{L}=\sqrt{ }\left(\left(\mathrm{x}_{3}{ }^{2} \mathrm{y}_{4}{ }^{2}+\mathrm{x}_{3}{ }^{2} \mathrm{z}_{4}{ }^{2}-2 \mathrm{x}_{3} \mathrm{y}_{4}{ }^{2} \mathrm{x}_{5}-2 \mathrm{x}_{3} \mathrm{z}_{1}{ }^{2} \mathrm{x}_{5}+\mathrm{y}_{4}{ }^{2} \mathrm{x}_{5}{ }^{2}+\mathrm{z}_{4}{ }^{2} \mathrm{x}_{5}{ }^{2}-2 \mathrm{x}_{3}{ }^{2} \mathrm{y}_{4} \mathrm{y}_{5}+2 \mathrm{x}_{3} \mathrm{x}_{4} \mathrm{y}_{4} \mathrm{y}_{5}+2 \mathrm{x}_{3} \mathrm{y}_{4} \mathrm{x}_{5} \mathrm{y}_{5}-\right.\right.$ $2 \mathrm{x}_{4} \mathrm{y}_{4} \mathrm{x}_{5} \mathrm{y}_{5}+\mathrm{x}_{3}{ }^{2} \mathrm{y}_{5}{ }^{2}-2 \mathrm{x}_{3} \mathrm{x}_{4} \mathrm{y}_{5}{ }^{2}+\mathrm{x}_{4}{ }^{2} \mathrm{y}_{5}{ }^{2}+\mathrm{z}_{4}{ }^{2} \mathrm{y}_{5}{ }^{2}+\mathrm{z}_{3}{ }^{2}\left(\mathrm{x}_{4}{ }^{2}+\mathrm{y}_{4}{ }^{2}-2 \mathrm{x}_{4} \mathrm{x}_{5}+\mathrm{x}_{5}{ }^{2}-2 \mathrm{y}_{4} \mathrm{y}_{5}+\mathrm{y}_{5}{ }^{2}\right)-2 \mathrm{x}_{3}{ }^{2} \mathrm{z}_{4} \mathrm{z}_{5}$ $+2 \mathrm{x}_{3} \mathrm{x}_{4} \mathrm{z}_{4} \mathrm{z}_{5}+2 \mathrm{x}_{3} \mathrm{z}_{4} \mathrm{x}_{5} \mathrm{z}_{5}-2 \mathrm{x}_{4} \mathrm{z}_{4} \mathrm{x}_{5} \mathrm{z}_{5}-2 \mathrm{y}_{4} \mathrm{z}_{4} \mathrm{y}_{5} \mathrm{z}_{5}+\mathrm{x}_{3}{ }^{2} \mathrm{z}_{5}{ }^{2}-2 \mathrm{x}_{3} \mathrm{x}_{4} \mathrm{z}_{5}{ }^{2}+\mathrm{x}_{4}{ }^{2} \mathrm{z}_{5}{ }^{2}+\mathrm{y}_{4}{ }^{2} \mathrm{z}_{5}{ }^{2}+\mathrm{y}_{4}{ }^{2}\left(\mathrm{x}_{4}{ }^{2}+\mathrm{z}_{4}{ }^{2}-\right.$ $\left.2 \mathrm{x}_{4} \mathrm{x}_{5}+\mathrm{x}_{5}{ }^{2}-2 \mathrm{z}_{4} \mathrm{z}_{5}+\mathrm{z}_{5}{ }^{2}\right)-2 \mathrm{y}_{3}\left(-\mathrm{x}_{4} \mathrm{y}_{4} \mathrm{x}_{5}+\mathrm{y}_{4} \mathrm{x}_{5}{ }^{2}+\mathrm{x}_{3}\left(\mathrm{x}_{4}-\mathrm{x}_{5}\right)\left(\mathrm{y}_{4}-\mathrm{y}_{5}\right)+\mathrm{x}_{4}{ }^{2} \mathrm{y}_{5}+\mathrm{z}_{4}{ }^{2} \mathrm{y}_{5}-\mathrm{x}_{4} \mathrm{x}_{5} \mathrm{y}_{5}+\right.$ $\left.\mathrm{z}_{3}\left(\mathrm{y}_{4}-\mathrm{y}_{5}\right)\left(\mathrm{z}_{4}-\mathrm{z}_{5}\right)-\mathrm{y}_{4} \mathrm{z}_{4} \mathrm{z}_{5}-\mathrm{z}_{4} \mathrm{y}_{5} \mathrm{z}_{5}+\mathrm{y}_{4} \mathrm{z}_{5}^{2}\right)-2 \mathrm{z}_{3}\left(\mathrm{z}_{4} \mathrm{x}_{5}{ }^{2}-\mathrm{y}_{4} \mathrm{z}_{4} \mathrm{y}_{5}+\mathrm{z}_{4} \mathrm{y}_{5}{ }^{2}+\mathrm{x}_{3}\left(\mathrm{x}_{4}-\mathrm{x}_{5}\right)\left(\mathrm{z}_{4}-\mathrm{z}_{5}\right)+\right.$ $\left.\left.\left.\mathrm{x}_{4}{ }^{2} \mathrm{z}_{5}+\mathrm{y}_{4}{ }^{2} \mathrm{z}_{5}-\mathrm{y}_{4} \mathrm{y}_{5} \mathrm{z}_{5}-\mathrm{x}_{4} \mathrm{x}_{5}\left(\mathrm{z}_{4}+\mathrm{z}_{5}\right)\right)\right) /\left(\mathrm{x}_{3}{ }^{2}+\mathrm{y}_{3}{ }^{2}+\mathrm{z}_{3}{ }^{2}-2 \mathrm{x}_{3} \mathrm{x}_{4}+\mathrm{x}_{4}{ }^{2}-2 \mathrm{y}_{3} \mathrm{y}_{4}+\mathrm{y}_{4}{ }^{2}-2 \mathrm{z}_{3} \mathrm{z}_{4}+\mathrm{z}_{4}{ }^{2}\right)\right)$

$\mathrm{L}:$ the dental arch length

$\left(x_{3}, y_{3}, z_{3}\right),\left(x_{4}, y_{4}, z_{4}\right)$ : the coordinates of the distal contact points of the right and left first molars

$\left(\mathrm{x}_{5}, \mathrm{y}_{5}, \mathrm{z}_{5}\right)$ : the coordinates of the mesial contact points of the right incisors

The measurements were repeated five times. Data were analyzed statistically with Student's t-test. Values to the second decimal place were regarded as valid.

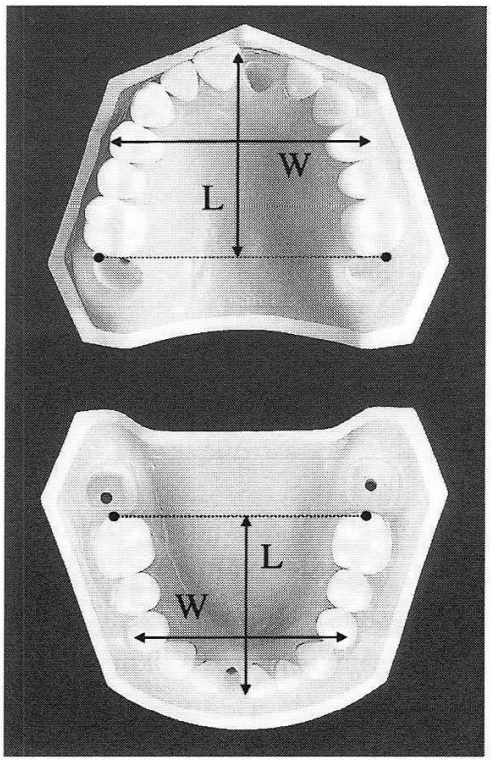

Fig. 6 Measurement of practical dentition model.

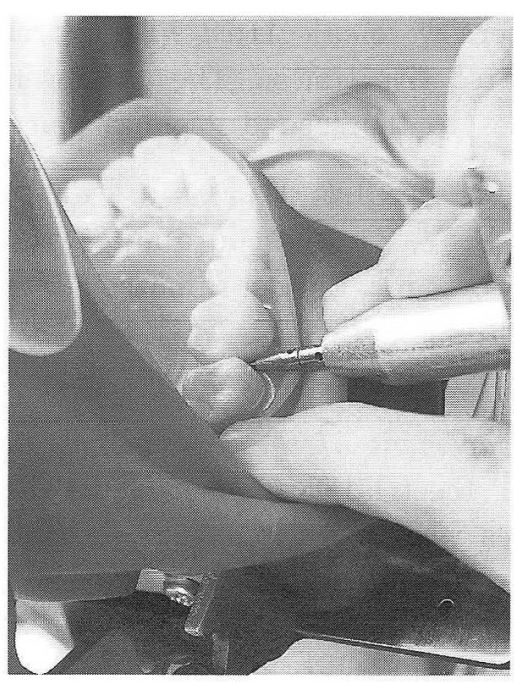

Fig. 7 Measuring scene. 


\section{RESULTS}

Operation of the trial teaching robot

The trial Teaching Robot operated easily with limited collisions of each of the links. The probe could be moved to optional points of the practical dentition model fixed to the manikin (Fig. 7). However, a slightly larger force was required for fixing the probe on measurements. Also, the cords that connected each encoder and the computer had a tendency to get entangled in the arm when the joints rotated many times in the same direction of the operation.

\section{The measurement results of the standard model}

With the trial Teaching Robot, the diameters of spheres $A, B$, and $C$ were $15.76 \mathrm{~mm}$, $15.86 \mathrm{~mm}$, and $12.04 \mathrm{~mm}$, respectively. The XYZAX G-800D measured the diameters of spheres A, B, and C as $15.992 \mathrm{~mm}, 15.994 \mathrm{~mm}$, and $12.000 \mathrm{~mm}$, respectively (Table 1 ). The results of the measurements were not significantly different.

\section{The measurement results of the practical dentition model}

The trial Teaching Robot measured the arch widths of both upper and lower jaws as $45.84 \mathrm{~mm}$ and $38.40 \mathrm{~mm}$, respectively. With the XYZAX G-800D, the arch widths of the upper and lower jaws were $45.858 \mathrm{~mm}$ and $38.423 \mathrm{~mm}$ (Table 2). The measurement results were not significantly different.

The trial Teaching Robot measured the arch lengths of the upper and lower jaws

Table 1 Diameters of spheres

\begin{tabular}{lcr}
\hline & Trial Teaching Robot & \multicolumn{2}{c}{ XYZAX-800D } \\
\hline Sphere A & $15.76(0.21)$ & $15.992(0.001)$ \\
Sphere B & $15.86(0.14)$ & $15.994(0.006)$ \\
Sphere C & $12.04(0.09)$ & $12.000(0.002)$ \\
\hline & ( ): Standard Deviation, Unit: $\mathrm{mm}$
\end{tabular}

Table 2 Widths of dental arches

\begin{tabular}{lcc}
\hline & Trial Teaching Robot & XYZAX-800D \\
\hline upper & $45.84(0.07)$ & $45.858(0.001)$ \\
lower & $38.40(0.21)$ & $38.423(0.003)$ \\
\hline & $($ ): Standard Deviation, Unit: $\mathrm{mm}$
\end{tabular}

Table 3 Lengths of dental arches

\begin{tabular}{lcc}
\hline & Trial Teaching Robot & XYZAX-800D \\
\hline upper & $36.50(0.37)$ & $36.441(0.003)$ \\
lower & $33.62(0.49)$ & $33.531(0.005)$ \\
\hline & ( ): Standard Deviation, Unit: $\mathrm{mm}$
\end{tabular}


as $36.50 \mathrm{~mm}$ and $33.62 \mathrm{~mm}$. The XYZAX G-800D measured the arch lengths of the upper and lower jaws as $36.441 \mathrm{~mm}$ and $33.531 \mathrm{~mm}$ (Table 3). The results of these measurements were not significantly different.

\section{DISCUSSION}

\section{The trial production process of the Teaching Robot}

Industrial art objects and folk craft articles are almost always made with skillful handwork. It is especially difficult to completely master advanced and exquisite production techniques. These techniques disappear if there is not a successor to carry on these skills. Therefore, the serious problem of how to pass on techniques has been alleviated by current technology. Recently, studies have tried these methods by entering techniques into the computer. Under the appropriate data set, objects are processed with a robot.

The Teaching Robot has been able to utilize exquisite techniques and maintain the accuracy of shapes through computer processing of data. The Teaching Robot was first developed by Makino et al. and had redundant degrees of freedom and joints (Fig. 8) ${ }^{23,24)}$. The Teaching Robot was composed of the right-hand system with seven degrees of freedom (seven links) and the left-hand system with two degrees of freedom (the rotary table on the work stand) (Fig.9). The movement of the probe was converted into numerical values and the position and posture of left and right human hands were entered into the computer. The working area was $350 \mathrm{~mm} \times 350$ $\mathrm{mm} \times 350 \mathrm{~mm}$. Two computers were used for data collection and analysis. Six degrees of freedom are needed for the robot to maintain its position and posture in space; specifically, three degrees of freedom for the position and three degrees of freedom for the posture. More than seven degrees of freedom were called the redundant degrees of freedom. Robots that have redundant degrees of freedom are enabled to move in the same way as human hands.

As for the Teaching Robot, the repeatability was $0.080 \mathrm{~mm}$, the positioning accuracy was $0.220 \mathrm{~mm}$, and the accuracy in $3-\mathrm{D}$ space was $0.250 \mathrm{~mm}$. The shapes of dental casts were measured with the Teaching Robot and many problems remained with its manipulation. For example, the arm was heavy and did not move quickly and smoothly ${ }^{25)}$.

The rotary table was removed and the new Teaching Robot was experimentally produced with only the right-hand system of seven degrees of freedom (Fig. 10, 11). The arm was made thin and short to improve its manipulation. The working area was limited to a cylinder, which included a diameter of $120 \mathrm{~mm}$ and a height of 50 $\mathrm{mm}$. The accuracy of measurement was improved. Namely, the repeatability was $0.040 \mathrm{~mm}$, the positioning accuracy was $0.134 \mathrm{~mm}$, and the accuracy in 3-D space was $0.074 \mathrm{~mm}$. However, it was difficult to measure the manipulator's blind spot ${ }^{26,27)}$. The rotary table was installed again (Fig. 12, 13), but the accuracy in 3-D space deteriorated. Because the arm was thin, it was feared that the first link was a lack of stiffness to support all the weight ${ }^{28)}$. 


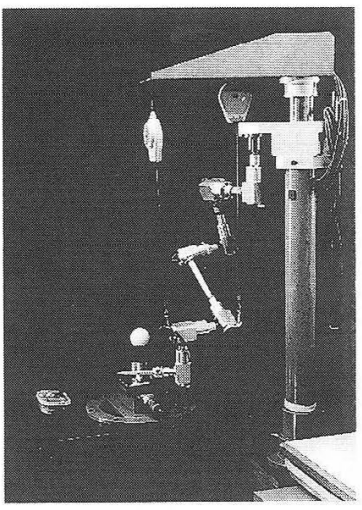

Fig. 8 Teaching robot No.1.

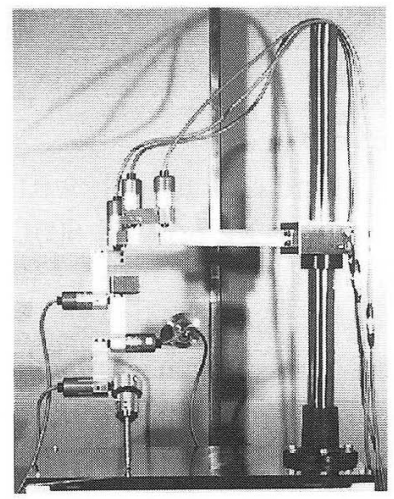

Fig. 10 Teaching robot No.2.

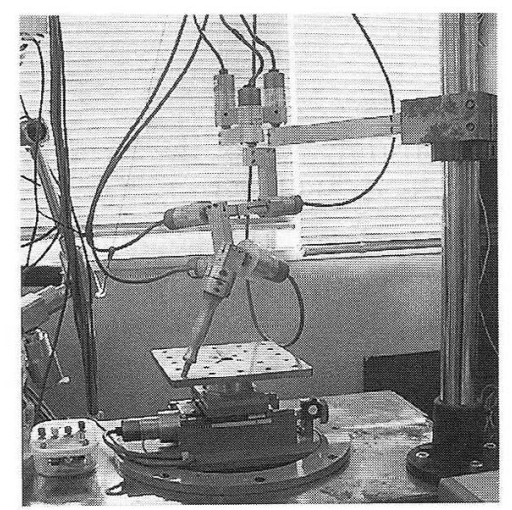

Fig. 12 Teaching robot improved No.2.

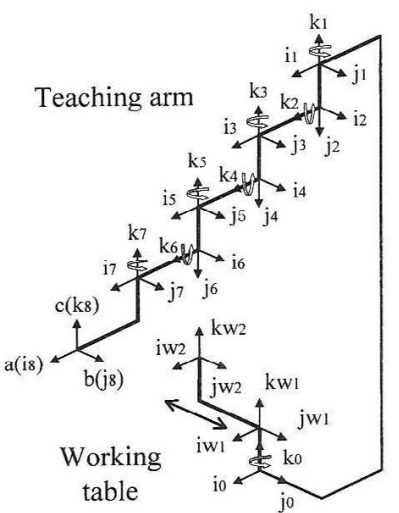

Fig. 9 Mechanism of teaching robot No.1.

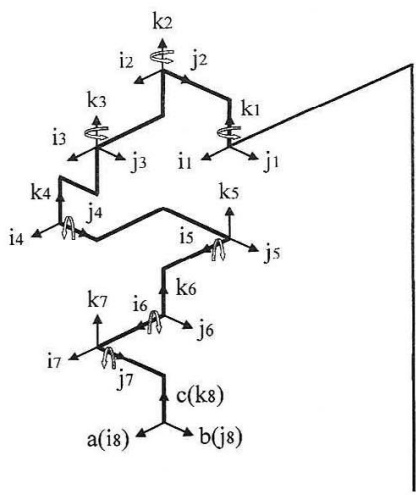

Fig. 11 Mechanism of teaching robot No.2.

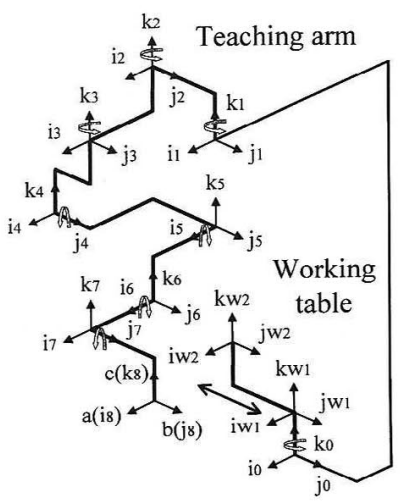

Fig. 13 Mechanism of teaching robot improved No.2. 
Based on these developmental processes, the trial Teaching Robot with six degrees of freedom was experimentally produced for this study. By keeping dental clinical use in mind, the structure became simpler. The main characteristics of the trial Teaching Robot were the following.

1 ) Light and stiff aluminum alloy was used for links.

2 ) Each of the links was firmly connected with two bearings to evade posture deviation with manipulation.

3 ) All links were made of the same structure to be able to change the length of links and the rotation axis as needed.

4 ) Encoders were included in the joints to avoid disturbances of the manipulation.

5 ) A spring counterbalance was used to reduce the effect of the weight of the arm on the manipulation.

6 ) An input button was installed on the grip of the probe to facilitate easier measurements.

7 ) A compatible PC was used for data collection and analysis to reduce space and costs.

\section{The measurement accuracy of the trial Teaching Robot}

The measurements of sphere diameters using the standard model with the trial Teaching Robot were similar to measurement data of the XYZAX G-800D. The results of measurement were not significantly different. Therefore, we expect that the trial Teaching Robot basically has superior measurement accuracy.

The widths and lengths of the practical dentition model arches measured in the oral cavity of the manikin were similar to the measurement data of the XYZAX G800D. The measurement accuracy was also confirmed in the oral cavity. The standard deviation revealed a slight trend to the large side because the probe had difficulty in repeatedly contacting the same position on the tops of the cusp and contact points that were measured. A slightly larger force was needed to fixate the probe in the measurements when using the trial Teaching Robot. Therefore, the weight of the arm seemed to have influenced the standard deviation.

\section{Application to the dental field and problems in the future}

It is possible to measure an optional position accurately with the trial Teaching Robot in this study. Therefore, it is expected that the Teaching Robot will be useful in the field of dentistry, especially in targets that are extremely complicated and in manifold shapes. Moreover, its superior accuracy is needed. In addition, it is possible to measure the undercut not measurable with a non-contact measuring apparatus. We suggest that the Teaching Robot can be immediately put to use in narrow oral cavities. For that purpose, it is necessary to miniaturize the whole measuring apparatus and to further improve its manipulation. As for practical measurement, it is necessary to investigate how to fix the head of the patient and to measure the same point over and over, and so on. Further, the trial Teaching Robot can take both the 
position and posture in space. If the hand-piece fixed on the Teaching Robot is used, it is possible to analyze the movement of the technician's hand.

The following is mentioned as one of the possible future applications. Needless to say, the study models used for dental clinical treatments are necessary and important. However, a lot of space is needed to keep them for a long period. It is very difficult in actuality and hence, it is a large problem. It would be useful a system is developed so that a study model is measured accurately, the data are saved in the computer and the study model is reconstructed with the spherical SCARA robot if necessary ${ }^{22,29-31)}$. In regard to the measuring, the trial Teaching Robot is prospective $^{32)}$. Furthermore, it is expected that direct measurements will be possible in the oral cavity without taking an impression for the study model. For example, it is expected that the Teaching Robot will be useful to understand the quantity of threedimensional movement of teeth in the orthodontic field.

It seems effective to use the non-contact type measuring apparatus with the contact type to face future problems. Both hard and soft tissues are targets in the dental area. Because soft tissue transforms with very little contact pressure of the probe, it is impossible to measure with the contact-type measuring apparatus. Therefore, the contact and non-contact types are combined with each other in the same coordinate system and each characteristic is utilized. Namely, the non-contact type is used in places that are suitable or sufficient and the contact type is used in places, such as the undercut, that cannot be measured and requires greater accuracy. We expect that it is possible to measure still more efficiently according to this purpose.

\section{CONCLUSION}

The articulated Teaching Robot with six degrees of freedom was experimentally produced in the development of a contact-type measuring apparatus that could be used directly in the oral cavity. A metal needle-shaped probe was installed and its manipulation was examined. Afterwards, a standard model was used to mimic the dentition by placing an arrangement of bearing balls. A practical dentition model fixed to a manikin was then measured. The accuracy was verified in comparison with the XYZAX G-800D.

Operation of the trial Teaching Robot was easy and there were limited collisions of each of the links. The probe could be moved to optional points of the practical dentition model that was fixed to a manikin. On the other hand, a slightly larger force was needed for fixing the probe on measurements.

The diameters of the three bearing balls on the standard model and the widths and lengths of the dental arches of the practical model were not significantly different from the results of the XYZAX G-800D. Therefore, we suggest that the trial Teaching Robot has superior efficiency for measurements.

Problems in the future may be addressed with the production of a miniaturized measuring apparatus with an improved manipulation and easier-to-use design. This 
type of measuring system could be widely-used in the field of clinical dentistry.

\section{REFERENCES}

1) Denissen, H., Dozic, A., van der Zel, J. and van Waas, M.: Marginal Fit and Short-Term Clinical Performance of Porcelain-Veneered CICERO, CEREC, and Procera Onlays, $J$ Prosthet Dent 84(5) : 506-513, 2000.

2) Usui, K., Mataki, S., Ikeuchi, H., Kurosaki, N., Shimizu, A. and Makino, H.: Study on Three-Dimensional Data Management System for Study Cast Part 2. A Divisional Measurement Method with Rotation, Jpn J Conserv Dent 40(1) : 294-297, 1997. (in Japanese)

3) Hirogaki, Y., Sohmura, T., Satoh, H., Takahashi, J. and Takada, K.: Complete 3-D Reconstruction of Dental Cast Shape Using Perceptual Grouping, IEEE Trans Med Imaging 20 (10) : 1093-1101, 2001.

4) Ikeuchi, H. and Kurosaki, N.: Study on Three-Dimensional Data Management System for Study Models Part 1. The Accuracy of Measurement for Standardized Stone Models, Jpn $J$ Conserv Dent 37(6): 1966-1971, 1994. (in Japanese)

5) Sohmura, T. and Takahashi, J.: Use of CAD/CAM System to Fabricate Dental Prostheses Part 1. CAD for A Clinical Crown Restoration, Int J Prosthodont 8(3) : 252-258, 1995.

6) Ikeuchi, H., Usui, K., Mataki, S. and Kurosaki, N.: Study on Measuring of The Facial Form Using 3-D Curved Shape Measurement Apparatus, Jpn J Conserv Dent 39(1): 163167, 1996. (in Japanese)

7) Ikeuchi, H.: A Fundamental Study on Measurement of Study Cast, Kokubyo Gakkai Zasshi 63(4): 620-628, 1996. (in Japanese)

8) Sohmura, T. and Takahashi, J.: CAD/CAM System to Fabricate Dental Prostheses-CAD for Bridge Restoration, Dent Meter J 16(1): 10-20, 1997.

9) Wakabayashi, K., Sohmura, T., Takahashi, J. Kojima, T., Akao, T., Nakamura, T., Takashima, F. and Maruyama, T.: Development of The Computerized Dental Cast Form Analyzing System--Three Dimensional Diagnosis of Dental Arch Form and The Investigation of Measuring Condition, Dent Mater $J$ 16(2): 180-190, 1997.

10) Kawahata, N., Ono, H., Nishi, Y., Hamano, T. and Nagaoka, E.: Trial of Duplication Procedure for Complete Dentures by CAD/CAM, J Oral Rehabil 24(7) : 540-548, 1997.

11) Denissen, H. W., van der Zel, J. M. and van Waas, M. A.: Measurement of The Margins of Partial-Coverage Tooth Preparations for CAD/CAM, Int J Prosthodont 12(5):395-400, 1999.

12) Kojima, T., Sohmura, T., Wakabayashi, K., Nagao, M., Nakamura, T., Takashima, F., Takahashi, J. and Maruyama, T.: Development of A New High-Speed Measuring System to Analyze The Dental Cast Form, Dent Mater J 18(4):354-365, 1999.

13) Sohmura, T., Kojima, T., Wakabayashi, K. and Nakamura, T.: Use of An Ultrahighspeed Laser Scanner for Constructing Three-Dimensional Shapes of Dentition and Occlusion, J Prosthet Dent 84(3) : 345-352, 2000.

14) Nagao, M., Sohmura, T., Kinuta, S., Kojima, T., Wakabayashi, K., Nakamura, T. and Takahashi, J.: Integration of 3-D Shapes of Dentition and Facial Morphology Using A High-Speed Laser Scanner, Int J Prosthodont 14(6) : 497-503, 2001.

15) Pfeiffer, J.: Dental CAD/CAM Technologies-The Optical Impression ( II ), Int $J$ Comput Dent 2(1): 65-72, 1999.

16) Iida, K., Inokoshi, S. and Kurosaki, N.: Marginal and Inside Adaptation of MOD Ceramic Inlay Made by Cerec 2 System, Jpn J Conserv Dent 42(6) : 1060-1065, 1999. (in Japanese)

17) Iida, K., Inokoshi, S. and Kurosaki, N.: Clinical Evaluation of Ceramic Inlays Made Using Cerec 2 System, Jpn $J$ Conserv Dent 43(1): 215-220, 2000. (in Japanese)

18) Yamaguchi, K.: Study on Improvement of Adaptation for Inlay Made by Dental CAD/ CAM CEREC 2 System, Kokubyo Gakkai Zasshi 67(2):163-168, 2000. (in Japanese)

19) Besimo, C., Jeger, C. and Guggenheim, R.: Marginal Adaptation of Titanium 
Frameworks Produced by CAD/CAM Techniques, Int $J$ Prosthodont 10(6) : 541-546, 1997.

20) May, K. B., Russell, M. M., Razzoog, M. E. and Lang, B. R.: Precision of Fit-The Procera AllCeram Crown, J Prosthet Dent 80(4):394-404, 1998.

21) Nakashima, T.: A Study on Application of Multiple Jointed Contact-Type Measuring Apparatus for Dental Use, Kokubyo Gakkai Zasshi 67(2):27-34, 2000. (in Japanese)

22) Usui, K., Mataki, S., Ikeuchi, H., Shimizu, A., Makino, H. and Kurosaki, N.: Study on Three-dimensional Data Management System for Study Cast Part 3. Trial for Reconstruction of the Standardized Stone Model, Jpn J Conserv Dent 40(2):745-748, 1997. (in Japanese)

23) Wang, S., Ming, A., Makino, H. and Shimizu, A.: Analisis and Calibration of Mechanical Errors of a Teaching Robot with Redundant Degrees-of-Freedom, Journal of the Japan Society for Precision Engineering 60(4) : 544-548, 1994. (in Japanese)

24) Wang, S., Terada, H., Makino, H. and Shimizu, A.: Study on Data Processing of a Teaching Robot with Redundant Degree-of-Freedom, Journal of the Japan Society for Precision Engineering 61(12): 1720-1724, 1995. (in Japanese)

25) Iwaki, J.: Study of Redundant Degrees of Freedom Teaching Robot, The Master's Thesis: Department of Mechanical System Engineering, Graduate School, Yamanashi University, 1995. (in Japanese)

26) Shimojima, S.: Trial Study of Teaching Machine, The Graduation Thesis: Department of Mechanical System Engineering, Graduate School, Yamanashi University, 1996. (in Japanese)

27) Yamaguchi, T.: Contact Measurement of Complicated Three-dimensional Shapes, The Graduation Thesis: Department of Mechanical System Engineering, Graduate School, Yamanashi University, 1998. (in Japanese)

28) Muramatsu, M.: Study about Improvement of Manipulation and Accuracy of Redundant Degrees of Freedom Teaching Robot, The Graduation Thesis: Department of Mechanical System Engineering, Graduate School, Yamanashi University, 1999. (in Japanese)

29) Ikeuchi, H., Usui, K., Mataki, S., Kurosaki, N., Shimizu, A. and Makino, H.: Study on Reconstruction of Facial Form, Jpn J Conserv Dent 39(2):542-546, 1996. (in Japanese)

30) Shimizu, A., Terada, H., Makino, H., Usui, K., Mataki, S. and Kurosaki, N.: ThreeDimensional Object Machining by a Robot Manipulator Part 1. Reconstruction Examples of Study Model of Teeth, Journal of the Japan Society for Precision Engineering 63(12) : 1747-1751, 1997. (in Japanese)

31) Usui, K.: Study on Reconstruction of Study Cast, Jpn J Conserv Dent 41(4) :683-689, 1998. (in Japanese)

32) Ming, A., Shimizu, A. and Makino, H.: Study on Robot Machining System for Industrial Art Objects, Journal of the Japan Society for Precision Engineering 60(1) : 91-96, 1994. (in Japanese) 